\title{
GESTÃo DE PESSOAS E AÇÕES DE PREVENÇÃO DO ASSÉDIO MORAL: OS CASOS DE DUAS COOPERATIVAS AGROPECUÁRIAS DO PARANÁ
}

\author{
RESOURCE MANAGEMENT AND PREVENTION OF MORAL
} HARASSMENT:THE CASES OF TWO AGRICULTURAL COOPERATIVES OF PARANÁ

\author{
Aline Alves Storti \\ Graduada em Administração pela Universidade Federal de Uberlândia - UFU, Minas Gerais, \\ (Brasil). E-mail: alinestorti@ hotmail.com

\section{Carlos Roberto Domingues} \\ Doutor em Administração de Empresas pela - Fundação Getúlio Vargas - FGV - EAESP-São \\ Paulo, (Brasil). Professor Adjunto da Faculdade de Gestão e Negócios - FAGEN, Uberlândia, \\ Minas Gerais, e na Universidade Federal de Uberlândia - UFU, Minas Gerais. E-mail: \\ carlosdomingues@yahoo.com
}

\section{Janaina Maria Bueno}

Doutora em Administração pela Fundação Getúlio Vargas - FGV, São Paulo, (Brasil). Professora Adjunta da Faculdade de Gestão e Negócios - FAGEN, Uberlândia, Minas Gerais e na Universidade Federal de Uberlândia UFU, Minas Gerais. E-mail: janainab@yahoo.com 


\section{GESTÃo DE PESSOAS E AÇÕES DE PREVENÇÃO DO ASSÉDIO MORAL: OS CASOS DE DUAS COOPERATIVAS AGROPECUÁRIAS DO PARANÁ}

\section{RESUMO}

Este estudo tem como objetivo identificar e analisar como são trabalhadas preventivamente as questões relativas ao assédio moral em duas cooperativas agropecuárias do Paraná. O lócus escolhido para análise justificou-se pela necessidade de ações que coíbam o assédio moral nas organizações e na peculiaridade do ambiente, além das duas cooperativas pesquisadas serem grandes empregadoras da sua região. A abordagem foi qualitativa, com estudo de casos, a pesquisa foi do tipo descritiva com coleta de dados por meio de pesquisa documental e entrevista com quatro gestores de duas cooperativas paranaenses. Como resultados, a pesquisa revelou que as duas cooperativas analisadas não possuem nenhum registro de assédio moral no Tribunal Regional do Trabalho, que elas utilizam alguns métodos de prevenção e que os discursos dos profissionais da área de gestão de pessoas apresentam algumas discrepâncias dos outros profissionais entrevistados que podem estar relacionadas ao desconhecimento do tema ou a aspectos culturais. A Cooperativa Verde apresentou mais métodos preventivos ao assédio moral que a Cooperativa Azul; dentre eles estão o código de ética, denúncias via $e$ mail, pesquisa de clima organizacional, caixa para denúncias e treinamento para futuros líderes abordando o tema do assédio. A Cooperativa Azul utiliza os canais formais de comunicação e diálogo com os funcionários, mas nada voltado diretamente para situações de assédio, pesquisa de clima organizacional, e código de ética. Sugere-se que as áreas de gestão de pessoas invistam mais na comunicação das ações de prevenção junto aos envolvidos, incentivando o diálogo e a disseminação do conhecimento sobre o que vem a ser o assédio e suas formas de prevenção.

Palavras chave: Assédio moral; Prevenção; Cooperativas agropecuárias. 


\title{
RESOURCE MANAGEMENT AND PREVENTION OF MORAL HARASSMENT: THE CASES OF TWO AGRICULTURAL COOPERATIVES OF PARANÁ
}

\begin{abstract}
The objective of this study was to identify and analyze how preventive work is done on issues related to moral harassment in two agricultural cooperatives in Paraná. The locus chosen for analysis was justified by the need for actions that curb harassment in organizations and by the peculiarity of the environment, in addition to the two cooperatives surveyed being large employers in their region. A qualitative case study approach was taken. Descriptive data was collected through document research and interviews with four managers of the two cooperatives. Findings revealed that both cooperatives analyzed have no records of moral harassment in the Regional Labor Court and use some prevention methods. In addition, statements by personnel management professionals presented some discrepancies with other professionals interviewed, which may be related to a lack of knowledge on the theme or to cultural aspects. The Green Cooperative presented more preventive methods to moral harassment than the Blue Cooperative, including a code of ethics, denunciations via e-mail, organization environment research, a denunciation box and harassment prevention training for future leaders. The Blue Cooperative uses formal channels of communication and employee dialogue, but nothing specifically directed towards situations of harassment, organization climate research, or a code of ethics. Areas of personnel management are suggested to invest more in communicating prevention actions with those involved, which encourages dialogue and the dissemination of knowledge on what harassment is and how to prevent it.
\end{abstract}

Keywords: Moral harassment; Prevention; Agricultural cooperatives. 


\section{INTRODUÇÃOO}

O fenômeno violência tem sido empregado em vários contextos da vida social e de diferentes formas. Rosa e Brito (2009) destacam alguns tipos de violência existentes como: a verbal, física, moral, policial, política, conjugal, social e organizacional. Dentre estes diferentes tipos de violência, a violência organizacional tem chamado mais atenção pelo aumento de situações que acarretam problemas para a dignidade e qualidade de vida dos trabalhadores. Observando o ambiente organizacional, Oliveira e Nunes (2008) buscaram distinguir os conceitos de violência do trabalho e violência no trabalho e afirmam que a violência do trabalho está relacionada às formas de organização do trabalho, ou seja, quando o processo causa sofrimento, desgaste e adoecimento ao trabalhador. Já a violência no ambiente de trabalho constituiu-se do contato entre violência e trabalho quando oferece risco para os trabalhadores.

O estudo da violência nas organizações foi necessário para o aprofundamento no tema do assédio moral, que não é um assunto novo, pelo contrário, é "tão antigo quanto o próprio trabalho" (Freitas, 2001, p.10). O assunto é recorrente nos dias atuais por ter alcançado dimensões globais, diferentes contextos de trabalho e diferentes tipos de profissionais. Por outro lado, há a preocupação em se pensar e agir de forma a prevenir o surgimento de situações de assédio e algumas ações são destacadas como sendo necessárias no ambiente organizacional (Hirigoyen, 2008; Nunes \& Tolfo, 2012).

Como um contexto organizacional específico, as cooperativas vêm crescendo em importância econômica e no número de empregos gerados. Segundo dados de Dias Júnior (2013), referentes ao ano de 2012, no Brasil havia 6.603 cooperativas atuantes em 13 ramos de atividade, com a geração de mais de 320 mil empregos diretos. O total de cooperados chegou a 11 milhões e 44 milhões representam o total de brasileiros envolvidos em atividades cooperativistas. Especificamente, tratando-se de cooperativas agropecuárias, para o mesmo período, a Organização das Cooperativas Brasileiras - OCB (2014) informa que são mais de 180 mil profissionais, onde o ramo agropecuário possui em torno de 1.500 cooperativas, sendo 74 no estado do Paraná com aproximadamente 68 mil empregados.

As cooperativas agropecuárias, no processo de acompanhar o crescimento do setor e a competitividade de seus mercados, passaram por um intenso processo de estruturação e profissionalização com a implementação de novas técnicas de gestão. Estas mudanças podem

Revista de Gestão e Secretariado-GeSec, São Paulo, v. 8, n. 1, p 71-100,jan./abr. 2017. 
acarretar em situações catalisadores de violência no ambiente de trabalho. Além disso, as cooperativas agropecuárias encontram-se localizadas no interior do Estado, onde são exemplo de conduta e de gestão para várias organizações no entorno. Por isso, foram contatadas cooperativas agropecuárias de grande porte localizadas no interior do Paraná, sendo que duas delas aceitaram participar da pesquisa. Assim, o presente trabalho tem como objetivo identificar e analisar quais são e como são tratadas as ações preventivas ao assédio moral em duas cooperativas agropecuárias paranaenses.

\section{REVISÃO DA LITERATURA}

\section{Violência relacionada ao Trabalho}

A violência pode ser definida como: “[...] evento representado por ações realizadas por indivíduos, grupos, classes ou nações que ocasionam danos físicos, emocionais, morais e/ou espirituais a si próprio ou a outros - por exemplo: agressão física, abuso sexual, violência psicológica, violência institucional” (Brasil, 2000, p. 427). Na visão de Campos (2004), a caracterização da violência depende de fatores como o contexto em que o fato ocorre e o julgamento de quem está como observador da situação. Para um fato ser considerado como uma violência, ele não pode ser apenas uma fatalidade e não pode possuir uma justificativa ou legitimação para o ocorrido. A violência é um ato desnecessário, injusto, ilegítimo e com caráter danoso, mas que pode ser evitado (Oliveira \& Nunes, 2008). Santos (2002) considera que a violência social contemporânea pode ser caracterizada como uma ação presente nas relações de poder que se manifestam tanto em indivíduos ou grupos sociais, em classes ou categorias sociais diferentes, em gêneros, etnias, grupos etários ou culturas distintas. E ela não se inicia ao acaso ou sem um propósito.

Segundo Arendt (1998), a violência necessita ser acompanhada de um fim, ou seja, uma razão que proporcione o direcionamento para o ato de violência que se torna um recurso para justificar a manutenção do poder, sendo o poder um fim e a violência um instrumento. A autora conceitua poder e violência como termos opostos, sendo que a completa afirmação de um revela a ausência do outro. Ou seja, a violência só se manifesta onde o poder está ameaçado e pode levar a sua desaparição, ele não pertence a um único indivíduo, mas sim a um grupo, sendo assim, o poder é uma habilidade de agir em comum acordo. Este poder apenas se mantém enquanto o grupo estiver unido, caso contrário, o poder desaparece.

Revista de Gestão e Secretariado-GeSec, São Paulo, v. 8, n. 1, p 71-100,jan./abr. 2017. 
Bourdieu (2010) discute o poder simbólico, no qual as classes dominantes impõem suas concepções e opiniões da realidade como sendo legítimas. Nesse contexto, a violência simbólica atua como uma violência invisível, suave a suas vítimas, que acontece por meio das vias simbólicas da comunicação e do conhecimento. Essa violência simbólica permite aprender a lógica da dominação, que ocorre de acordo com uma maneira de falar, um estilo de vida, um princípio simbólico e mais comumente de um emblema, conhecido pelo dominante e pelo dominador. E, um ambiente que, além de ser propício ao surgimento dos diferentes tipos de violência, também se torna o seu catalisador, isto é, dando-lhe nova energia, é o da produção capitalista.

Oliveira e Nunes (2008) afirmam que na produção capitalista, o trabalho acaba assumindo um caráter de exploração, uma vez que este ocorre em um ambiente de interesses contraditórios entre quem vende o trabalho e quem é explorado. Assim, o poder é realizado por aquele que possui o capital, sem necessitar de uma relação que legitime o exercício. $O$ sistema opera de forma controladora na vida do indivíduo, principalmente naqueles que trabalham em grandes corporações, ou naquelas que estão vivendo momentos de crescimento. Com isso, o indivíduo se torna um meio de produção, deixando-se coisificar, sendo considerado assim como o maior ativo da empresa que, utiliza formas para manipular sua subjetividade em beneficio próprio. Mesmo com este sistema de exploração, o indivíduo procura manter-se nele com receio de acabar desempregado (Siqueira, 2009).

Ao relacionar a violência ao trabalho Oliveira e Nunes (2008) citam como sendo uma atitude voluntária de uma pessoa ou grupo contra outra pessoa ou grupo que possa causar danos físicos ou psicológicos, dentro do ambiente de trabalho ou que seja relacionado ao trabalho. Outras formas de violência relacionada ao trabalho citadas pelos autores são a omissão das condições de trabalho, omissão de cuidados e solidariedade diante de acontecimentos como morte ou adoecimento relacionados ao trabalho, supressão e desrespeito às normas e direitos trabalhistas e previdenciários. Relacionadas à violência no trabalho, algumas subcategorias são relacionadas como: violência nas relações de trabalho, violência na organização do trabalho, violência nas condições de trabalho, violência de resistência, violência de delinquência e violência simbólica. O Quadro 1 a seguir define de forma resumida estes tipos. 
Quadro 1 - Tipos de violência relacionada ao trabalho

\begin{tabular}{|l|l|}
\hline Tipos & Características \\
\hline Violência nas relações & $\begin{array}{l}\text { Engloba as ocasiões em que a autoridade se converte em uma hierarquia de } \\
\text { desigualdade, em que o autoritarismo surge e acaba levando a reações explícitas de } \\
\text { agressão física, constrangimentos, humilhações de superiores para com seus } \\
\text { subordinados. Tem como objetivo a dominação, opressão e exploração do } \\
\text { indivíduo. Pode ser dividida em física ou psicológica. A violência psicológica ainda } \\
\text { se divide em três categorias: ameaça assédio e bullying. }\end{array}$ \\
\hline Violência & $\begin{array}{l}\text { Faz referência à forma como o trabalho é organizado, ou seja, quando a divisão do } \\
\text { trabalho, a jornada, os sistemas de segurança e saúde e outras formas de } \\
\text { organização do trabalho }\end{array}$ \\
\hline $\begin{array}{l}\text { Violência nas condições } \\
\text { de trabalho }\end{array}$ & $\begin{array}{l}\text { Ocorre quando o ambiente e as condições de trabalho são inapropriados e inseguros } \\
\text { para o trabalhador. }\end{array}$ \\
\hline Violência de resistência & $\begin{array}{l}\text { Acontece quando os trabalhadores se voltam contra as violências que sofrem no } \\
\text { trabalho, buscando manifestar resistência ao poder e controle dos superiores. }\end{array}$ \\
\hline $\begin{array}{l}\text { Violência } \\
\text { delinquência }\end{array}$ & $\begin{array}{l}\text { Ocorre quando atos criminosos são praticados por funcionários ou por pessoas } \\
\text { alheias à organização. }\end{array}$ \\
\hline Violência simbólica & $\begin{array}{l}\text { Ocorre quando os funcionários são discriminados por sua cor, raça, escolaridade ou } \\
\text { falta de qualificação profissional. }\end{array}$ \\
\hline
\end{tabular}

Fonte: Adaptado de Oliveira e Nunes (2008, pp. 30-31).

Pinto e Paula (2013) trabalham o conceito de violência interpessoal que acontece por meio da agressão física e/ou discursiva e/ou por meio de comportamentos e/ou atitudes que sejam prejudiciais ao indivíduo. A violência interpessoal acontece no ambiente por meio da interconexão entre duas ou mais pessoas e se caracteriza como violência independente dos atos de agressão serem intencionais ou não. De forma complementar, a abordagem sobre a violência simbólica se faz necessária para que não se limite a violência ao âmbito das interações diretas entre os indivíduos.

Decorrente da violência no trabalho têm-se outros estudos que ao se aprofundarem oferecem uma compreensão mais amiúde e aprofundada sobre aspectos que, embora interligados devem ser trabalhados de forma individualizada, assim o é com o assédio moral.

\section{Assédio Moral}

É descrito como uma ação perversa que tem como objetivo massacrar o outro com situações humilhantes e de forma constante. Embora ocorram nas relações pessoais, as Revista de Gestão e Secretariado-GeSec, São Paulo, v. 8, n. 1, p 71-100,jan./abr. 2017. 
organizações têm se tornado palco para tais ações (Farias, 2008). No ambiente organizacional pode ser definido como um apanhado de práticas reiteradas que estão dentro dos métodos de gestão e que por meio de humilhações, constrangimentos e pressões controlam o trabalhador para que ele cumpra os objetivos da empresa (Gosdal, Soboll, Schatzmam \& Eberle, 2009). Segundo Gonçalves (2008), engloba o constrangimento por meio de gestos, palavras, ações e violência física tanto no convívio social como no trabalho. Constitui-se por um conjunto de ações abusivas com o objetivo de atingir e ameaçar a integridade física e psíquica do indivíduo por meio da sua repetição.

Não é possível negar que é um problema organizacional, para Nunes e Tolfo (2012) as organizações são responsáveis pela prevenção de tais comportamentos. Aposentadorias precoces, indenizações, baixa produtividade, tratamentos médicos e psicológicos podem ser causados pela ineficiência da organização em prevenir o assédio. Em Freitas (2001), há uma clara sinalização para esta percepção, quando afirma que todos nós somos capazes de utilizar nosso lado perverso para destruir o outro, mas a repetição e a frequência dessas atitudes é que ocasionam o assédio moral. O agressor cresce diante do rebaixamento do outro, assim muitos só existem pela destruição do outro na sede de demonstrar poder, ter admiração e aprovação:

[...] uma observação mais ferina, em um dado momento de nervosismo ou de mau humor, não é significativa, especialmente se vem seguida de um pedido de desculpas pelo excesso. É a repetição das situações que vexam o outro e das humilhações sem nenhuma nuance que constitui o fenômeno destruidor (Freitas, 2001, p. 10).

O assédio moral não pode ser confundido com estresse ou a uma humilhação feita pela hierarquia uma única vez, ele é um ato que acontece de forma duradoura. Ainda segundo a autora "segundo o dicionário, assediar é 'submeter sem repouso a pequenos ataques repetidos" (Hirigoyen, 2008, p.17) e ela define o assédio moral no trabalho: “[...]como toda conduta abusiva (gesto, palavra, comportamento, atitude...) que atenta, por sua repetição ou sistematização, contra a dignidade ou a integridade psíquica ou física de uma pessoa, pondo em perigo seu emprego ou degradando o ambiente de trabalho" (Hirigoyen, 2008, p. 19).

Assim, para entender como o assédio moral funciona, Hirigoyen (2006) argumenta que ele tem como objetivo atacar e até mesmo se livrar de indivíduos que fogem das normas de um grupo. Os indivíduos submetidos ao assédio são formatados para que alcancem os objetivos e desempenhos esperados pela empresa. Para que isso ocorra diversas formas sãoutilizadas, por meio de brincadeiras discriminatórias na não aceitação da diferença, Revista de Gestão e Secretariado-GeSec, São Paulo, v. 8, n. 1, p 71-100,jan./abr. 2017. 
comportamentos invejosos, de ciúme ou rivalidade, por medo ou por comportamentos que ocultem problemas, como detalhado no Quadro 2, a seguir.

Quadro 2 - Formas de assédio e como ocorrem

\begin{tabular}{|c|c|}
\hline Formas de assédio & Como ocorrem? \\
\hline Recusa da distinção & $\begin{array}{l}\text { Em comportamentos sexistas com brincadeiras para desestimular uma mulher a ocupar } \\
\text { um cargo que é tipicamente considerado masculino. } \\
\text { Quando um grupo não aceita um indivíduo pelo fato ele agir, pensar, falar ou vestir de } \\
\text { forma diferente do grupo. } \\
\text { Acontece quando um grupo rejeita pessoas pouco produtivas ou produtivas demais. }\end{array}$ \\
\hline Inveja & $\begin{array}{l}\text { A inveja é um sentimento natural, mas difícil de ser reconhecido pelas pessoas que o } \\
\text { fazem e que, ao invés disso, tentam destruir, difamar, ou tentam alcançar o patamar em } \\
\text { que o ser invejado está. A inveja pode ocorrer por pequenas coisas como: inveja pela } \\
\text { mesa perto da janela ou inveja da pessoa que é preferida pelo chefe. }\end{array}$ \\
\hline Ciúmes & $\begin{array}{l}\text { Ocorrem quando uma pessoa já não tem segurança sobre si mesma e não entende porque } \\
\text { um subordinado possui mais diplomas que ele mesmo. }\end{array}$ \\
\hline Rivalidade & $\begin{array}{l}\text { Ocorre quando as empresas colocam uma pessoa contra a outra, como exemplo, os } \\
\text { jovens contra os mais velhos para que estes últimos saiam prejudicados. }\end{array}$ \\
\hline Medo & $\begin{array}{l}\text { É normalmente pelo medo que uma pessoa se torna violenta. Assim uma pessoa pode } \\
\text { agredir outra por se sentir ameaçada. }\end{array}$ \\
\hline O inconfessável & $\begin{array}{l}\text { Nas organizações existem regras explícitas e implícitas e o não cumprimento de tais } \\
\text { regras pode levar o indivíduo a rejeição pelo grupo. São fatos não ditos, não discutidos, } \\
\text { regras ocultas que pertencem ao grupo e que para eles devem ser respeitados. A pessoa } \\
\text { que denunciar será rejeitada. Como exemplo, roubo de materiais de escritório, utilização } \\
\text { do telefone da empresa para fins pessoais etc. }\end{array}$ \\
\hline
\end{tabular}

Fonte: Adaptado de Hirigoyen (2006, pp. 37-51).

Tais formas de assédio moral utilizam-se de métodos que se configuram, dentre outros, em: deterioração proposital das condições de trabalho; isolamento e recusa de comunicação; atentado contra a dignidade; e violência verbal, física ou sexual, de acordo com Hirigoyen (2006). Os métodos podem variar de acordo com as formas de assédio, que são de um superior hierárquico para um subordinado, entre colegas, de um subordinado para um superior hierárquico ou misto.

O assédio vertical descendente acontece de forma quando os superiores agridem seus subordinados. Esse tipo de assédio pode ter consequências mais graves para a saúde do trabalhador do que o assédio horizontal, visto que a vítima se sente isolada e tem dificuldades 
de encontrar uma solução. Essa situação vinda dos superiores ainda pode ser classificada em três tipos: perverso, estratégico e institucional. Já o vertical ascendente ocorre quando um ou mais subordinados agridem um superior. $\mathrm{O}$ assédio ascendente pode ocorrer de duas formas: falsa alegação de assédio sexual e por reações coletivas de grupo. As vítimas do ascendente não sabem a quem pedir ajuda, tornando o problema mais difícil de ser conhecido e resolvido. O horizontal é descrito quando um colega agride outro colega; frequentemente ocorre pela competição de um cargo ou promoção. E o assédio misto ocorre quando ambos os tipos ocorrem simultaneamente, tanto de forma vertical como horizontal (Hirigoyen, 2006).

$\mathrm{O}$ assédio afeta e causa problemas à vida psíquica, profissional, familiar, social e afetiva, além de gerar problemas de saúde e psicossomáticos que podem ter duração variável todos eles, independente da forma e sentido (Freitas, 2008). No mesmo sentido, Gonçalves (2008) considera que ele pode ser prejudicial não só ao trabalhador, também à família deste trabalhador e toda a sociedade como um todo, além de poder ocasionar danos à personalidade, à integridade física e psíquica e à dignidade. As alterações provocadas podem ser percebidas pela de falta de atenção, indução ao erro, depressão, pensamentos autodestrutivos e até mesmo tentativas de suicídio (Freitas, 2008). E pode ocasionar o dano moral, que é imediato ao acontecimento e o dano psíquico, que é cumulativo e pode gerar sintomas piores para a saúde, de acordo com Gonçalves (2008). Quando o assédio é recente e existe a possibilidade de se contornar tal situação, os sintomas são parecidos com o estresse, que leva as pessoas a ficarem mais nervosas, cansadas, com problemas digestivos, dores de cabeça, dores na coluna e distúrbios no sono. Porém, se continua por mais tempo, um processo depressivo mais grave pode se fortalecer, levando o assediado a apresentar tristeza, complexo de culpa, apatia e desinteresse por seus valores (Hirigoyen, 2006).

Outros problemas mencionados por Nunes e Tolfo (2012) para o indivíduo são alterações no sono, aumento da pressão arterial, insegurança, enjoos, consumo excessivo de drogas e álcool, raiva, descontentamento com o trabalho, falta de apetite, dores esporádicas, vontade de chorar, manifestações depressivas, abandono de relações pessoais. As consequências não são apenas para o indivíduo, a organização também é afetada com aposentadorias prematuras, absenteísmo dos funcionários, exposição negativa do nome da empresa, redução da produtividade e do desempenho, alta rotatividade de pessoal.

Para Hirigoyen (2006), as consequências do assédio moral também afetam as esferas sociais e econômicas, em $36 \%$ dos casos é seguido da saída da vítima da empresa. As pessoas 
desempregadas e com dificuldades de conseguir emprego, muitas vezes levam marcas do assédio moral sofrido em outros empregos, os sintomas dessas marcas vão desde o estresse até a perda de identidade. Logo, as pessoas marcadas por situações de assédio acabam perdendo a confiança em si mesmas e tornando-se desconfiadas e desmotivadas, ocasionando uma dificuldade na procura de um novo emprego. As consequências econômicas vão desde a perda da renda para a pessoa desempregada, despesas médicas, necessidade de tratamento psicoterápico e despesas com advogado. Para a coletividade, as consequências são despesas de saúde por parte do seguro social, hospitalizações, indenizações e aposentadorias antecipadas.

\section{Prevenção ao Assédio}

$\mathrm{O}$ assédio moral deve ser prevenido pela organização por meio de um ambiente seguro e saudável para o trabalhador. O empregador é responsável por garantir um ambiente de trabalho seguro e que garanta todos os diretos ao trabalhador, permitindo que ele tenha sua dignidade e saúde para desempenhar suas funções. Entende-se que o ambiente livre de violência e que gere bem-estar ao trabalhador é uma responsabilidade da organização (Barreto 2004; Teixeira, Munck \& Reis, 2011).

Assim, a criação de um código de ética para as organizações é um dos métodos que podem ser usados para prevenção do assédio moral, além da criação de espaços de amparo às vítimas, nos quais as denúncias possam ser feitas em sigilo (Barreto, 2004), ou mecanismos que permitam que o trabalhador denuncie o agressor em sigilo por meio de urnas (Heloani, 2004). Também é preciso que as condições de trabalho sejam constantemente revisadas para não gerar um ambiente demasiado competitivo e que acarrete violência.

Logo, as organizações devem buscar soluções que permitam maior participação e autonomia dos trabalhadores em suas jornadas de trabalho, evitando assim rotinas repetitivas, monótonas e extensas no ambiente de trabalho, de acordo com Barreto (2004). Outra ação que pode ser utilizada pelas organizações como forma de prevenção e combate ao assédio é a criação de um espaço para discussão dos problemas, ou seja, por meio de reuniões mensais, por exemplo, os membros poderiam expor seus problemas e suas angustias de forma que todos os outros membros possam entender e enxergar que o problema relatado pode ser do grupo ou da organização e não do indivíduo (Heloani, 2004).

Revista de Gestão e Secretariado-GeSec, São Paulo, v. 8, n. 1, p 71-100,jan./abr. 2017. 
Entretanto, para Freitas, Heloani e Barreto (2008), a tarefa de acabar com a violência no trabalho é coletiva e necessita da cooperação dos cargos mais elevados da organização. $\mathrm{O}$ envolvimento da alta gestão é importante para que o assunto seja discutido com seriedade e sem omissões. Complementarmente, existe o método de combate social que se dá por meio de leis. Para Hirigoyen (2008), a lei é necessária, mas deve-se lembrar de que a lei não resolverá tudo. Ainda existirão indivíduos para enganar a lei e agir em benefício próprio. Com isso, são necessárias outras ações que possam prevenir as práticas de assédio. Uma prevenção eficaz deve atuar não somente sobre as pessoas, mas também sobre os métodos de gestão da empresa (Hirigoyen, 2008). Seguindo esta linha, Nunes e Tolfo (2012), ao ser constatada uma prática de assédio, os gestores primeiramente não devem punir o agressor ou agressores, deve-se buscar acabar com qualquer comportamento hostil e estabelecer um clima justo de trabalho. Após o ocorrido, deve-se investigar o fato, dialogar com todos os envolvidos e analisar alguns pontos:

[...] a) Se o assédio ocorreu e como prevenir que ele ocorra; b) Se não é assédio, pode ser outra coisa (exemplo: estresse, conflitos interpessoais, enganos), se for, trabalhar para restaurar boas condições de trabalho para todos; c) Quais condições e práticas organizacionais são necessárias alterar com intuito de prevenir futuros maus tratos ou cenários de assédio moral. (Nunes \& Tolfo, 2012, p.7).

Hirigoyen (2006) nos fala sobre os intervenientes para casos de assédio que podem ser internos e externos. Os internos são compostos pelos sindicatos, os CHSCT (comitês de higiene, segurança e condições de trabalho), os médicos do trabalho, os diretores de recursos humanos e os consultores temporários. No âmbito externo estão compostos por clínicos gerais, psiquiatras e psicoterapeutas, a fiscalização do trabalho, os conselheiros dos assalariados, os advogados, as associações e a ARACT (Agência Nacional para melhoria das condições de trabalho).

Também cabem as empresas de grande porte que têm poder de influência em relação à sociedade à qual fazem parte e também em relação às empresas menores, portanto de acordo com Teixeira, Reis e Santos (2013), estas devem servir de exemplo positivo a fim de evitar casos de assédio. Ainda de acordo com os mesmos autores todos os níveis hierárquicos das empresas devem ter consciência sobre o que é o assédio por meio de informativos, palestras, além de oferecer os meios para denúncias que preservam a identidade das vítimas. Os códigos de ética ou conduta comumente disponíveis nas empresas não garantem que as organizações 
estarão isentas de casos de assédio, ao contrário, deve-se manter o constante acompanhamento por parte dos gestores. Em sua pesquisa sobre formas de prevenir e combater o assédio, Nunes e Tolfo (2012) categorizaram as ações de combate ao assédio em três dimensões: diagnóstico organizacional, estratégias de prevenção e ações de intervenção, conforme o Quadro 3.

Quadro 3 - Medidas de prevenção e combate ao assédio moral

\begin{tabular}{|c|c|c|}
\hline Diagnóstico organizacional & Prevenção & Intervenção \\
\hline $\begin{array}{l}\text { Avaliar os fatores de riscos } \\
\text { psicossociais. }\end{array}$ & $\begin{array}{l}\text { Promover mudanças na } \\
\text { cultura organizacional. }\end{array}$ & $\begin{array}{l}\text { Criar espaço de confiança dentro da } \\
\text { empresa (comitês, canais de escuta) para } \\
\text { que o trabalhador possa expressar suas } \\
\text { queixas. }\end{array}$ \\
\hline $\begin{array}{l}\text { Refletir sobre a forma de } \\
\text { organização de trabalho e seus } \\
\text { métodos de gestão de pessoal. }\end{array}$ & $\begin{array}{l}\text { Educar e capacitar gerentes, } \\
\text { pessoas-chave e líderes. }\end{array}$ & $\begin{array}{l}\text { Estabelecer um terceiro imparcial } \\
\text { (mediador) dentro da empresa. }\end{array}$ \\
\hline $\begin{array}{l}\text { Refletir acerca das práticas } \\
\text { organizacionais e da cultura } \\
\text { organizacional, averiguando } \\
\text { possibilidades de mudanças. }\end{array}$ & $\begin{array}{l}\text { Criar um código de conduta, } \\
\text { código de ética, incluir normas } \\
\text { de conduta. }\end{array}$ & $\begin{array}{l}\text { Aplicar medidas disciplinares e/ou } \\
\text { sanções aos agressores e empregadores. }\end{array}$ \\
\hline $\begin{array}{l}\text { Realizar pesquisas com os } \\
\text { funcionários. }\end{array}$ & $\begin{array}{l}\text { Promover práticas que } \\
\text { estimulem o respeito, } \\
\text { colaboração e integração entre } \\
\text { os funcionários. }\end{array}$ & $\begin{array}{l}\text { Identificar e avaliar uma situação de } \\
\text { assédio moral, buscando intervir de } \\
\text { forma contextualizada, de acordo com a } \\
\text { fase na qual a situação se encontra. }\end{array}$ \\
\hline $\begin{array}{l}\text { Verificar o ambiente } \mathrm{e} \\
\text { acompanhar a equipe. }\end{array}$ & $\begin{array}{l}\text { Conscientizar e disseminar } \\
\text { informações sobre assédio. }\end{array}$ & Proteger judicialmente a vítima. \\
\hline $\begin{array}{l}\text { Realizar discussões formais e } \\
\text { informais da avaliação com os } \\
\text { funcionários. }\end{array}$ & $\begin{array}{l}\text { Educar e capacitar } \\
\text { funcionários. }\end{array}$ & $\begin{array}{l}\text { Minimizar as consequências para a } \\
\text { vítima (fornecer apoio psicológico, } \\
\text { definir estratégia terapêutica, práticas } \\
\text { alternativas, conscientização grupal). }\end{array}$ \\
\hline $\begin{array}{l}\text { Acompanhar o absenteísmo, as } \\
\text { reclamações e as faltas por } \\
\text { doença. }\end{array}$ & $\begin{array}{l}\text { Desenvolver comunicação } \\
\text { interna, promover o diálogo, } \\
\text { grupos de debate, espaços de } \\
\text { escuta. }\end{array}$ & $\begin{array}{l}\text { Formar uma equipe para lidar com o } \\
\text { assédio de maneira coordenada e } \\
\text { multidisciplinar. }\end{array}$ \\
\hline $\begin{array}{l}\text { Utilizar medidas psicométricas } \\
\text { como forma de diagnosticar } \\
\text { assédio moral no trabalho. }\end{array}$ & Reduzir o estresse. & $\begin{array}{lllr}\text { Possuir conselheiros } & & \text { internos } \\
\text { independentes capazes de } & \text { prover } \\
\text { informação da política } & \text { e } & \text { dos } \\
\text { procedimentos. } & & & \end{array}$ \\
\hline Investigar a dimensão e natureza & Criar ambiente; melhorar as & Demonstrar à organização que o assédio \\
\hline
\end{tabular}

Revista de Gestão e Secretariado-GeSec, São Paulo, v. 8, n. 1, p 71-100,jan./abr. 2017. 
Gestão de Pessoas e Ações de Prevenção do Assédio Moral: Os Casos de Duas Cooperativas Agropecuárias do Paraná

\begin{tabular}{|c|c|c|}
\hline do problema. & $\begin{array}{l}\text { condições garantir qualidade } \\
\text { de vida no trabalho. }\end{array}$ & $\begin{array}{l}\text { moral é um fenômeno complexo e que } \\
\text { todos saem perdendo: indivíduo, } \\
\text { organização e sociedade. }\end{array}$ \\
\hline $\begin{array}{l}\text { Realizar pesquisa de clima } \\
\text { organizacional. }\end{array}$ & $\begin{array}{l}\text { Possibilitar autonomia para } \\
\text { organizar o trabalho, fornecer } \\
\text { informações e recursos } \\
\text { necessários para execução das } \\
\text { tarefas e reduzir o trabalho } \\
\text { monótono e repetitivo. }\end{array}$ & $\begin{array}{l}\text { Coibir comportamentos inadequados que } \\
\text { conduzam ao assédio. }\end{array}$ \\
\hline \multirow[t]{2}{*}{ Questionar a forma de gestão. } & $\begin{array}{l}\text { Aumentar } \\
\text { fiscalização/controle dos } \\
\text { funcionários. }\end{array}$ & $\begin{array}{l}\text { Ter procedimentos especiais para casos } \\
\text { em que os envolvidos são de diferentes } \\
\text { níveis hierárquicos. }\end{array}$ \\
\hline & $\begin{array}{l}\text { Dar exemplo de } \\
\text { comportamento e/ou conduta } \\
\text { adequada e promover } \\
\text { mudanças na organização que } \\
\text { combatam ao assédio. }\end{array}$ & $\begin{array}{l}\text { Tornar visível as situações de assédio } \\
\text { moral por parte dos trabalhadores. }\end{array}$ \\
\hline
\end{tabular}

Fonte: Adaptado de Nunes e Tolfo (2012).

No âmbito interno das organizações o diagnóstico organizacional é utilizado para detectar e apontar se o ambiente organizacional pode favorecer a sua ocorrência e a intervenção busca agir para cessar e amenizar as ocorrências para a vítima e também punir os agressores. Para que essas ações sejam analisadas, identificadas e desenvolvidas pela empresa é preciso o envolvimento e comprometimento de toda a organização (Nunes \& Tolfo, 2012).

\section{PROCEDIMENTOS METODOLÓGICOS}

A pesquisa foi de abordagem qualitativa, o procedimento técnico da pesquisa foi estudo de casos e a coleta de dados foi realizada por meio de entrevistas semiestruturadas, realizadas por telefone, em que cada um dos participantes foi contatado, primeiramente, por meio eletrônico (e-mail) para agendamento do telefonema de entrevista. Também, foi realizada a pesquisa documental via sites das empresas e documentos, como código de ética e documentos sobre processos trabalhistas, na base de dados da $9^{\text {a }}$ Região do Tribunal Regional do Paraná - por onde tramitam todos processos que poderiam envolver estas cooperativas - o resultado estará descrito após o quadro resumo das análises das entrevistas.

Revista de Gestão e Secretariado-GeSec, São Paulo, v. 8, n. 1, p 71-100,jan./abr. 2017. 
Quanto à análise de dados, o estudo utilizou a análise de conteúdo (Bardin, 2011), com uso de técnicas para interpretação dos dados. Segundo Dellagnelo e Silva (2005), nas pesquisas qualitativas, com o uso de técnicas mais ou menos refinadas, esta forma de análise tem sido uma das mais utilizadas no campo da administração no Brasil. Assim, após coletados os dados, eles foram preparados por meio da transcrição das entrevistas e organização dos documentos levantados, e feita a leitura flutuante. Em seguida, foram explorados e analisados, com a consequente categorização dos achados por meio da codificação o que facilitou o processo de interpretação. E, finalmente foram apresentados em quadros analíticos que permitiram a construção dos elementos de análise deste artigo.

Foram estudadas duas cooperativas agropecuárias do estado do Paraná. Por motivos de preservação os nomes das cooperativas foram alterados, sendo assim, serão apresentadas como Cooperativa Verde e Cooperativa Azul. A escolha se deu em função das cooperativas paranaenses, além de apresentarem crescimento econômico financeiro nos últimos anos passaram por um interessante processo de reestruturação organizacional e serem exemplo de conduta e gestão nas regiões onde atuam, no interior do Estado. Tais cooperativas, em especial, enquadram-se neste critério e porque ambas as cooperativas são grandes empregadoras das cidades onde estão localizadas e são reconhecidamente importantes referências na região. Logo, as políticas de gestão de gestão de pessoas tornam-se exemplos para outras empresas, principalmente para aquelas diretamente ligadas às cooperativas.

O roteiro para as entrevistas foi baseado na fundamentação teórica sobre a prevenção ao assédio moral, questionando quais as ações e medidas que servem como mecanismos de apoio, se existe código de ética, se a cooperativa realiza pesquisa de clima organizacional, se existe a conscientização dos funcionários a respeito do que é o assédio, quais os espaços de escuta para os funcionários, se o ambiente de trabalho é seguro e saudável e outras perguntas relacionadas às ações preventivas. O Quadro 4 apresenta o perfil dos respondentes: 
Gestão de Pessoas e Ações de Prevenção do Assédio Moral: Os Casos de Duas Cooperativas Agropecuárias do Paraná

Quadro 4 - Respostas dos entrevistados às questões iniciais da pesquisa

\begin{tabular}{|c|c|c|c|c|}
\hline & $\begin{array}{l}\text { Gestora GP- } \\
\text { Cooperativa Azul }\end{array}$ & $\begin{array}{l}\text { Gestor 2 - } \\
\text { Cooperativa Azul }\end{array}$ & $\begin{array}{l}\text { Gestor RH- } \\
\text { Cooperativa } \\
\text { Verde }\end{array}$ & $\begin{array}{l}\text { Gestora 2- } \\
\text { Cooperativa } \\
\text { Verde }\end{array}$ \\
\hline $\begin{array}{ll}\text { Qual } & \text { sua } \\
\text { formação? } & \end{array}$ & $\begin{array}{l}\text { Economia e Psicologia } \\
\text { com pós em RH. }\end{array}$ & Engenheiro Agrícola & $\begin{array}{l}\text { Economia, } \\
\text { contábeis e direito. }\end{array}$ & $\begin{array}{l}\text { Processamento de } \\
\text { dados. }\end{array}$ \\
\hline $\begin{array}{l}\text { Qual cargo } \\
\text { ocupa? }\end{array}$ & $\begin{array}{l}\text { Supervisora de Gestão } \\
\text { de Pessoas. }\end{array}$ & $\begin{array}{l}\text { Gerente de Negócios } \\
\text {-Carnes }\end{array}$ & $\begin{array}{l}\text { Gerência de } \\
\text { Recursos Humanos } \\
\text { e de Advogado. }\end{array}$ & $\begin{array}{l}\text { Coordenadora da } \\
\text { área de tecnologia } \\
\text { da informação. }\end{array}$ \\
\hline $\begin{array}{l}\text { Quanto tempo } \\
\text { está neste cargo? }\end{array}$ & 2 anos. & 10 anos. & 20 anos. & 6 meses. \\
\hline $\begin{array}{l}\text { E quanto tempo } \\
\text { está } \\
\text { empresa? }\end{array}$ & 20 anos. & 19 anos. & 26 anos. & 20 anos. \\
\hline $\begin{array}{l}\text { Possui } \\
\text { relacionamento } \\
\text { com a chefia? Se } \\
\text { sim, qual o nível } \\
\text { da relação? }\end{array}$ & $\begin{array}{l}\text { Sim, subordinada a um } \\
\text { coordenador e depois a } \\
\text { uma diretoria. }\end{array}$ & $\begin{array}{l}\text { Sim, relação de } \\
\text { subordinação direta } \\
\text { com o Diretor de } \\
\text { Operações. }\end{array}$ & Sim, gerente-geral. & $\begin{array}{l}\text { Sim, subordinada } \\
\text { ao gerente } \\
\text { administrativo- } \\
\text { financeiro. }\end{array}$ \\
\hline $\begin{array}{l}\text { No caso de } \\
\text { gerentes, } \\
\text { quantas pessoas } \\
\text { coordena? }\end{array}$ & $\begin{array}{l}\text { Supervisiona } \\
\text { pessoas. }\end{array}$ & $\begin{array}{l}\text { Coordena no geral } \\
170 \text { pessoas. }\end{array}$ & 20 pessoas. & 23 pessoas. \\
\hline
\end{tabular}

Fonte: dados de pesquisa.

Outra questão importante para se observar é que foram respeitadas as nomenclaturas adotadas para a área de gestão de pessoas utilizadas pelas cooperativas. Neste caso, a Cooperativa Azul adota a nomenclatura de Gestão de Pessoas, enquanto a Cooperativa Verde adota Recursos Humanos. Tal medida não retrata os aspectos epistemológicos do uso dos termos.

\section{APRESENTAÇÃO E ANÁLISE DOS DADOS}

\section{O Ambiente Organizacional em Cooperativas Agropecuárias}

As cooperativas agropecuárias possuem um papel relevante nas esferas econômica e social, devido ao fato de, em muitas regiões significarem uma forma de agregação de valor ao 
cenário produtivo rural, como também permitirem que pequenos e médios produtores entrem em mercados maiores e mais concentrados. Com as mudanças no ambiente político e econômico brasileiro nas décadas de 1980 e 1990, as cooperativas tiveram de se ajustar a fim de ampliar ou manter suas participações no mercado. Assim em um ambiente de negócios cada vez mais acirrado, as cooperativas necessitam cooperar não somente com seus associados, mas também com outras cooperativas, conforme é denominado o princípio da intercooperação (Ferreira \& Braga, 2004; Lago \& Silva 2012),

Para superar as mudanças ocorridas, as cooperativas utilizaram-se de estratégias competitivas para sobreviver e aumentar sua participação no mercado igualando-se, de muitas formas, às empresas tradicionais. Para tornarem-se competitivas frente aos concorrentes e ao mercado em geral, adotaram formas e instrumentos de gestão tradicionais, mas ao mesmo tempo, elas possuem algumas características próprias e desafios como definir o seu processo decisório, dando mais autonomia aos gestores ou não, a tomada de decisão compartilhada entre os cooperados, a visão de curto, médio e longo prazo, o papel dos cooperados como fornecedores e sócios da cooperativa e a relação entre estes e os empregados da cooperativa (Bialoskorski Neto, 2002; Chaddad, 2007; Ferreira \& Braga, 2004). O crescimento do agronegócio nos últimos anos tem levado as cooperativas a rever suas estratégias, estruturas e modelos de gestão (Bialoskorski Neto, 2002).

Em relação ao cenário das cooperativas agropecuárias, Dias Júnior (2013), revela que existiam do período de jan./dez. de 2012, 1.561 cooperativas no ramo agropecuário e que a participação destas cooperativas na produção nacional é de $48 \%$. Os produtos que as cooperativas apresentam maior participação na produção brasileira são trigo (74\%), soja (57\%), café (48\%), algodão (44\%), milho (43\%), arroz (35\%) e feijão (18\%). E os benefícios do cooperativismo agropecuário são: agregação de valor e eficiência na cadeia produtiva, economias de escala, prestação de serviços e acesso à tecnologia e a mercados.

A realidade do agronegócio, conforme apresentada anteriormente, instiga saber a respeito de sua institucionalização e de aspectos relacionados a gestão das cooperativas. Assim, a seguir, será trabalhado o contexto das cooperativas no que tange a sua história e os resultados da pesquisa.

A Cooperativa Verde iniciou suas atividades no início do século passado com a vinda de algumas famílias de pioneiros europeus que fundaram uma cooperativa de produção de manteiga e queijo. Entre 1950 e 1960, juntaram-se à Cooperativa Verde mais duas cooperativas agropecuárias da região, também formadas por pioneiros europeus, o que Revista de Gestão e Secretariado-GeSec, São Paulo, v. 8, n. 1, p 71-100,jan./abr. 2017. 
garantiu maior impulso aos negócios. Uma delas foi a cooperativa Azul e juntas, as três cooperativas fundaram uma cooperativa central com a finalidade de organizar em maior escala a produção, a industrialização e o comércio de produtos como leite e derivados. Mais tarde, o grupo estendeu sua atuação para o setor de carnes (suínos e aves).

Na década de 1980, a Cooperativa Verde tornou-se uma das organizações modelo do segmento no estado do Paraná. Atualmente, a Cooperativa possui um amplo portfólio de atividades de produtos e serviço. São eles: assistência técnica agrícola, farmácia veterinária, loja de peças agropecuárias, postos de combustíveis, lojas de insumos, bovinos de leite, leite a granel, suínos, rações, assistência técnica pecuária, semente de soja e trigo e soja não OGM (Organismo Geneticamente Modificado).

A Cooperativa Azul também foi fundada por imigrantes europeus e fica distante cerca de trinta quilômetros, aproximadamente, da Cooperativa Verde. Possui produção agrícola e atividade de pecuária leiteira e de carne. Atualmente, possui unidades em diferentes cidades do Paraná e no Estado de São Paulo.

Com base também nas respostas obtidas nas entrevistas, os gestores de ambas as cooperativas afirmaram que o ambiente de trabalho dos empregados é considerado bom. $\mathrm{Na}$ Cooperativa Azul afirmaram que são feitos trabalhos e investimentos para questões ergométricas e processo de avaliação de relacionamentos, já na Cooperativa Verde foi mencionado o uso de pesquisa de clima organizacional anualmente.

A primeira pergunta buscou identificar como os gestores percebem seu ambiente de trabalho e como o avaliam. Os quatro gestores afirmaram que trabalham em um bom ambiente organizacional e não relataram nenhum problema a este respeito. Eles afirmaram que as organizações buscam garantir um ambiente seguro e saudável para seus trabalhadores. Sobre a Cooperativa Verde afirmou-se que há um sistema que integra gestão ambiental, gestão da qualidade e gestão da segurança do trabalho. E a resposta do Gestor 2 descreve as ações da Cooperativa Azul:

Gestor 2, Cooperativa Azul: [...] a cooperativa tem investido nos últimos anos em um sistema de gestão integrada do qual um de seus pilares é o bem-estar e a segurança de seus funcionários[...].

Percebe-se, a partir das respostas, que as cooperativas buscam estar de acordo com as leis e normas em respeito à saúde e bem-estar de seus empregados. Tal fato vai ao encontro da 
afirmação de Barreto (2004), de que o empregador é responsável por garantir um ambiente de trabalho seguro e que garanta todos os diretos ao trabalhador, permitindo que este tenha sua dignidade e que tenha saúde para desempenhar suas funções. Sobre os direitos dos trabalhadores, as cooperativas cumprem a legislação trabalhista de forma geral e ressaltou-se a existência de acordos coletivos com o sindicato no caso da Cooperativa. A gestora de Gestão de Pessoas da Cooperativa Azul frisou que na organização há a preocupação em cumpri-los.

Com base em Campos (2004), de que a caracterização da violência depende de fatores como o contexto em que o fato ocorre e o julgamento de quem está como observador da situação foi questionado como os gestores viam os desentendimentos entre colegas de trabalho. Na Cooperativa Azul, os gestores afirmaram que os desentendimentos existem, mas que os que não forem de cunho profissional não são bem-vistos, a partir daí o chefe de cada área tenta solucionar o atrito e a área de Gestão de Pessoas também é envolvida. $\mathrm{Na}$ Cooperativa Verde, o gestor de RH afirmou que são feitos treinamentos para capacitar os líderes a lidar com essas situações e caso o líder não consiga resolver o problema, a área de recursos humanos é chamada. Compreende-se que os gestores de ambas as cooperativas buscam tentar resolver os conflitos dentro da própria área em que ocorreu o fato, mas caso não obtenham sucesso a área de recursos humanos é sempre envolvida para tentar sanar o problema.

Sobre a existência de um código de ética em cada cooperativa, todos responderam que há sim, e segundo as suas normas internas, o código é passado para os empregados no momento de sua integração à organização. Conforme observado por Heloani (2004), o código de ética é um dos métodos que podem ser usados para prevenção do assédio moral, pois eles explicitam as condutas e esclarecem qual é o comportamento considerado correto e esperado dos empregados.

Quanto ao questionamento sobre quais são as ações e as medidas que podem ocorrer como mecanismos de prevenção para situações de assédio, os gestores da Cooperativa Azul relataram que não há ação ou medida estruturada e a gestora de GP afirmou que:

Gestora de Gestão de Pessoas, Cooperativa Azul: [...] Hoje não existe nenhum “mecanismo", por causa que não tivemos, pelo menos para mim nunca foi passado nada sobre (haver) assédio”. 
Já na Cooperativa Verde o gestor de RH afirmou que existe o código de ética como elemento de apoio e medida balizadora de condutas, além disso informou que:

Gestor de RH, Cooperativa Verde: Tem as denúncias que você pode fazer via $e$-mail e a pesquisa de clima organizacional inclusive, que a gente dá um ID para cada funcionário, onde que ele pode falar sobre a sua chefia, condutas da sua chefia, em relação a questão moral, em relação a questão ética de ação.

Ou seja, de acordo com o Gestor de RH existem ações de prevenção a situações de assédio, a Gestora 2, porém, afirma não ter conhecimento de nenhum justificando que: "Gestora 2, Cooperativa Azul: [...] mas é que a gente também não tem esse tipo de problema, né![...]".

Sobre as ações preventivas de assédio tanto Barreto (2004) quanto Heloani (2004) afirmam que as organizações devem criar espaços de amparo às vítimas, nos quais as denúncias possam ser feitas em sigilo. Como foi observado, apenas o gestor de RH da Cooperativa Verde afirmou existir esta ação e parece que isso não está claro para todos.

Para os gestores que responderam não existirem ações de prevenção para casos de assédio moral, foi questionado se as cooperativas pensam em adotar algum método de prevenção e se sim quais. Foram obtidas as seguintes respostas:

Gestora Gestão de Pessoas, Cooperativa Azul: ““'Eu acredito que sim, porque a gente está bem no interiorzão, então não é muito falado sobre o assunto. Mas, a cooperativa está expandindo pra São Paulo e lá a gente já percebe que o pessoal tem outra cultura e eles buscam bastante, qualquer coisa que está errado, eles já tão reclamando, questionando, querendo informações. Então, a cooperativa tem que estar atualizada e antenada nessa situação, sim.

Gestor 2, Cooperativa Azul: Não tem sido tema de discussões.

Gestora 2, Cooperativa Verde: Eu acredito que se, digamos esse tipo de incidência começar a acontecer e começar a ser frequente, com certeza (será feito algo).

A pergunta sobre como cada cooperativa responderia caso acontecesse alguma situação de assédio foi respondida apenas por três gestores: 
Gestora GP, Cooperativa Azul: '[...]Com certeza, ela iria [...] punir os autores no caso, porque a cooperativa é muito justa, os dirigentes gostam das coisas bem corretas, os valores para eles são coisas que são assim importantíssimas [...]. Então, com certeza a cooperativa faria uma verificação e puniria os infratores. De alguma forma com advertência, suspensão, desligamento e para a pessoa injustiçada ela iria de alguma forma bonificar essa pessoa, não sei exatamente como, né! [...].

Gestor 1, Cooperativa Azul: Casos que venham ocorrer serão tratados com superiores.

Gestora 2, Cooperativa Verde: É, eu acho que ela seria um pouco extrema na parte da pessoa que assedia. Até, digamos assim alguma demissão, alguma coisa nesse sentido.

Percebe-se que, os gestores acreditam que caso ocorra alguma situação de assédio, as cooperativas tomariam, sim, alguma providência, e que haveria punição para o assediador. Mas de acordo com Nunes e Tolfo (2012) o correto a fazer quando constatada uma prática de assédio é não punir o agressor ou agressores, primeiro deve-se buscar acabar com qualquer comportamento hostil e estabelecer um clima justo de trabalho no primeiro momento e posteriormente tomar as devidas providências.

A próxima pergunta foi sobre a posição da cooperativa após um caso de assédio. Se a cooperativa tornaria o fato conhecido para todos ou não. Os gestores da Cooperativa Azul afirmaram que a empresa não tornaria o fato visível, mas que se surgisse a história na mídia, ela iria tentar se defender. Já na opinião dos gestores da Cooperativa Verde:

Gestor RH, Cooperativa Verde: Depende do assédio, se for um assédio que não tivesse impacto negativo na imagem e exposição do assediado ou do assediante, sim né. Agora se fosse algo que destruísse a vida familiar do assediador ou do assediado, aí a cooperativa se resguardaria no direito de limitar o caso somente as duas partes.

Gestora 2, Cooperativa Verde: Eu acredito que não. Justamente pela nossa cultura, que não é algo que a gente estaria alarmando e colocando em risco a imagem da cooperativa. Mas sim, eu acredito que faria internamente um trabalho junto com os coordenadores e gestores, mas não tornaria público todo esse processo.

Apesar de algumas discrepâncias, observou-se convergência em pensar que uma situação de assédio não se tornaria pública por parte das cooperativas. Estas percepções vão 
na direção oposta do que Nunes e Tolfo (2012) comentam sobre ser a forma adequada de intervenção para casos de assédio que é tornar o fato visível para os trabalhadores.

Questionados sobre a existência de algum tipo de treinamento para gestores e líderes para lidar com casos de assédio, os entrevistados da Cooperativa Azul afirmaram que não existe nenhum treinamento específico para estes casos. Porém um dos gestores afirmou que “[...] Eu vejo como algo que existe não formalizado, mas está embutido na cultura da empresa", ou seja, para este gestor o treinamento não é formalizado, mas que se subentende estar na cultura da cooperativa. Por outro lado, na Cooperativa Verde, o gestor de recursos humanos afirmou existir o treinamento que é feito anualmente e onde são abordados temas como o papel do líder, o perfil do líder, as normas que o líder deve respeitar e como ele deve se portar em casos que ele ocorra. Ao contrário do gestor de recursos humanos, a gestora da área de tecnologia afirmou nunca ter participado ou ouvido falar desse tipo de treinamento.

Em relação ao treinamento de gestores e líderes para lidar com situações de assédio, Hirigoyen (2006) afirma que este é o terceiro passo do planejamento de prevenção ao assédio: "treinamento de funcionários do Departamento de Recursos Humanos quanto às providências a adotar para prevenir o assédio moral, detectá-lo ou administrar os casos já existentes" (Hirigoyen, 2006, p. 326). Percebe-se assim, que ter líderes preparados para tratar com situações de assédio deixa as organizações mais bem estruturadas para resolver tais casos. Além disso, os gestores têm o papel de interceder previamente quando perceberem que alguma situação pode ocasionar o assédio, evitando assim problemas maiores.

Outro ponto de análise da pesquisa foi identificar se as cooperativas estudadas promovem práticas para conscientizar e disseminar informações a respeito do assédio para seus empregados. A gestora de GP da Cooperativa Azul afirmou que já houve palestras, mas de forma muito vaga. $\mathrm{O}$ gestor 2 da Cooperativa Azul afirmou não ter nada. $\mathrm{Na}$ Cooperativa Verde, o gestor de RH afirmou que essas práticas são passadas no momento da integração do empregado à empresa por meio do código de ética e da disseminação da cultura. A gestora de tecnologia afirmou não conhecer nada. Nesse caso, uma das partes mais importantes da prevenção é a informação, pois é por meio dela que os empregados podem entender o que é de fato o assédio moral e tomar precauções com relação às suas atitudes e também estarem atentos quando acontecer com eles ou com pessoas próximas. Hirigoyen (2006) frisa a importância de campanhas explicativas e debates públicos para todos os empregados de uma organização a fim de levar informação e conhecimento.

Revista de Gestão e Secretariado-GeSec, São Paulo, v. 8, n. 1, p 71-100,jan./abr. 2017. 
Foi questionado também se as cooperativas estimulam o diálogo, promovem grupos de debate ou espaços de escuta para seus funcionários. Com base nesta pergunta, a gestora de GP da Cooperativa Azul afirmou que existe o diálogo de segurança semanalmente, o "espaço do colaborador" que ocorre mensalmente e onde o empregado pode falar sobre sua família e seu trabalho. Há também a intranet, onde cada um pode escrever sobre assuntos do seu interesse. Já o outro gestor entrevistado da Cooperativa Azul, afirmou não existir nenhum espaço de escuta ou diálogo para os funcionários.

$\mathrm{Na}$ Cooperativa Verde, o gestor de recursos humanos respondeu afirmando ter um programa chamado de "PDL (Programa de Desenvolvimento de Lideranças)" que é desenvolvido para os futuros líderes ou aqueles que têm potencial para exercer cargos de chefia; nesse programa os potenciais líderes recebem treinamento, em que é abordado o tema. A outra gestora entrevistada da Cooperativa Verde afirmou que não existe.

E uma das últimas perguntas para tentar identificar ações preventivas para o assédio moral foi se as cooperativas realizam pesquisa de clima organizacional. Sobre isso, os respondentes afirmaram existir pesquisa de clima organizacional. Sobre os resultados aferidos, a gestora de recursos humanos da Cooperativa Azul reafirmou que

Gestora de GP, Cooperativa Azul: [...] nunca houve, não teve nada que indicasse que tenha ocorrido, que tenha alguma coisa que indique assédio [...].

O gestor de recursos humanos da Cooperativa Verde revelou que o questionamento sobre assédio moral na pesquisa de clima organizacional é feito de forma direta, como relatada por ele:

Gestor de RH, Cooperativa Verde: [...] a pergunta é bem direta: você já sofreu assédio moral da sua chefia?

$\mathrm{O}$ gestor de $\mathrm{RH}$ afirmou que na última pesquisa de clima todos os participantes afirmaram não ter sofrido assédio moral. Ele afirmou que as pesquisas são realizadas anualmente, enquanto que a gestora que não é de RH afirmou que as pesquisas são realizadas a cada dois anos. 
O Quadro 5 sintetiza a análise das respostas, comparando-as entre si:

Quadro 5 - Resumo dos pontos mais importantes revelados pela entrevista

\begin{tabular}{|c|c|}
\hline $\begin{array}{l}\text { Ações de prevenção de } \\
\text { situações de assédio }\end{array}$ & $\begin{array}{l}\text { Ambos os gestores da Cooperativa Azul concordam que não existe nenhuma ação } \\
\text { preventiva para situações de assédio e justificam dizendo que nunca houve casos de } \\
\text { assédio moral. Na Cooperativa Verde há afirmações contraditórias dos dois } \\
\text { entrevistados, o gestor de Recursos Humanos afirmou existir ações de prevenção e } \\
\text { citou-as. Já a segunda entrevistada afirmou não ter conhecimento de nenhuma ação } \\
\text { de prevenção e justificou que não existe porque a cooperativa nunca sofreu casos de } \\
\text { assédio. Fatores como a má comunicação ou a falta dela podem estar causando essa } \\
\text { contradição nas respostas dos entrevistados. }\end{array}$ \\
\hline $\begin{array}{l}\text { Treinamento para } \\
\text { gestores e líderes sobre } \\
\text { assédio moral }\end{array}$ & $\begin{array}{l}\text { Ambos os entrevistados da Cooperativa Azul responderam que não existe nenhum } \\
\text { treinamento para gestores e líderes sobre assédio moral, novamente, as respostas } \\
\text { foram semelhantes. } \mathrm{Na} \text { Cooperativa Verde, os gestores discordam em suas } \\
\text { respostas. O gestor de Recursos Humanos afirma existir o treinamento anual, } \\
\text { enquanto a gestora afirma desconhecer. Tal divergência pode ser justificada por } \\
\text { vários fatores como, por exemplo, a falta de informações sobre os treinamentos. }\end{array}$ \\
\hline $\begin{array}{lr}\text { Práticas } & \text { para } \\
\text { disseminar } & \text { e } \\
\text { conscientizar os } & \\
\text { funcionários } & \text { sobre } \\
\text { assédio moral } & \end{array}$ & $\begin{array}{l}\text { A gestora de Gestão de Pessoas da Cooperativa Azul afirmou que já houve, mas de } \\
\text { forma vaga. Enquanto que o Gestor afirmou apenas que não existem. Na } \\
\text { Cooperativa Verde novamente houve a contradição das respostas, onde a área de } \\
\text { recursos humanos afirma existir a conscientização dos funcionários sobre o assédio, } \\
\text { a gestora que não pertence ao RH desconhece tal fato. }\end{array}$ \\
\hline $\begin{array}{l}\text { A cooperativa oferece: } \\
\text { Grupos de debate, } \\
\text { espaços de escuta e } \\
\text { estímulo ao diálogo? }\end{array}$ & $\begin{array}{l}\text { Na Cooperativa Azul, a gestora de GP afirma-se que existe espaço para diálogo que } \\
\text { a cooperativa oferece aos funcionários. Por outro lado, o gestor que não pertence ao } \\
\text { Recursos Humanos afirma que não existem tais ações. Na Cooperativa Verde a } \\
\text { gestora que não pertence à área de RH afirma que existe por meio da pesquisa de } \\
\text { satisfação. E o gestor de RH afirma que acontece por meio do treinamento que é } \\
\text { oferecido para futuros líderes. Novamente houve discordância entre as opiniões. }\end{array}$ \\
\hline $\begin{array}{l}\text { Planejamento para } \\
\text { adoção de métodos de } \\
\text { prevenção ao assédio } \\
\text { moral }\end{array}$ & $\begin{array}{l}\text { A gestora de GP da Cooperativa Azul afirma que a cooperativa vai buscar a adoção } \\
\text { de métodos de prevenção ao assédio moral; um dos motivos é a expansão da } \\
\text { empresa. Por outro lado, o outro gestor afirmou não ter conhecimento. Nesse caso, a } \\
\text { contradição das respostas é justificável, pois como o tema de planejamento sobre } \\
\text { prevenção a casos de assédio compete mais à área de recursos humanos, as outras } \\
\text { áreas podem desconhecer o fato até que ele seja devidamente planejado e } \\
\text { implementado na empresa em geral. Na Cooperativa Verde, a gestora que não é de } \\
\text { RH desconhece a existência de ações de prevenção e afirma que se houver casos de } \\
\text { assédio, a cooperativa tomaria medidas preventivas. Já o gestor de RH revelou que } \\
\text { já existem métodos preventivos ao assédio. }\end{array}$ \\
\hline
\end{tabular}

Fonte: dados de pesquisa.

Revista de Gestão e Secretariado-GeSec, São Paulo, v. 8, n. 1, p 71-100,jan./abr. 2017. 
Além das discrepâncias entre as respostas, principalmente dos respondentes da Cooperativa Verde, observou-se que as respostas dos gestores de recursos humanos foram mais contundentes que a dos gestores que não são desta área.

Como resultado da pesquisa feita na base de dados do Tribunal Regional do Paraná, averiguou-se que nenhuma das duas cooperativas teve algum processo trabalhista com reclamatórias sobre assédio moral e ou sexual. Isto corrobora as informações repassadas pelos gestores de RH de não haver histórico formal sobre esta questão nas cooperativas Azul e Verde.

\section{CONSIDERAÇÕES FINAIS}

O objetivo geral deste trabalho foi identificar e analisar como são tratadas preventivamente as questões relativas ao assédio moral pelas cooperativas agropecuárias no Paraná. Foi constatado que nas duas cooperativas estudadas há métodos de tratamento preventivo para o assédio moral. Na Cooperativa Azul, há espaços de escuta e diálogo para os funcionários, mas nada voltado diretamente para situações de assédio, é feita pesquisa de clima organizacional, além de haver código de ética. Na Cooperativa Verde, as ações preventivas identificadas foram: código de ética, denúncias via e-mail, pesquisa de clima organizacional, caixa para denúncias e treinamento para futuros líderes abordando o tema do assédio.

Ao se comparar as visões das cooperativas pesquisadas e assinalar as diferenças, identificou-se que as cooperativas não possuem visões diferentes, apenas existe a diferença nas ações entre as cooperativas. Por exemplo, a Cooperativa Verde possui mais métodos preventivos para casos de assédio, ao contrário da Cooperativa Azul que utiliza apenas o código de ética e pesquisa de clima organizacional, e justifica que não existem mecanismos preventivos porque nunca houve casos de assédio na cooperativa. E os achados, ou melhor, o fato de não haver reclamações trabalhistas envolvendo ambas as cooperativas, sinaliza que as ações adotadas são efetivas no sentido de minimizar o contencioso trabalhista.

E, quando se comparam as visões dos gestores entrevistados de cada Cooperativa, conclui-se que os gestores da área de Gestão de Pessoas de ambas as cooperativas mostraram mais segurança em suas respostas além de buscar justificá-las. Ao contrário, os outros dois entrevistados que não eram da área de gestão de pessoas, na maioria das perguntas, relataram desconhecer os métodos de prevenção e não demonstraram tanta preocupação com o assunto. Revista de Gestão e Secretariado-GeSec, São Paulo, v. 8, n. 1, p 71-100,jan./abr. 2017. 
As discrepâncias entre as respostas de gestores da área de Gestão de Pessoas e de outros gestores que não da área podem ser justificadas pela área de trabalho de cada gestor nas cooperativas. Os gestores da área de Gestão de Pessoas lidam diretamente com assuntos relacionados aos indivíduos, como formas de recrutamento e seleção, remuneração, treinamentos, bem-estar dos funcionários, entre outros aspectos, então, estão diretamente ligados ao tema e compete a estes profissionais prevenir, intervir e resolver tais problemas. Já os gestores que não são da área de Gestão de Pessoas revelam desconhecer métodos preventivos ao assédio moral justamente por não trabalharem diretamente com tais assuntos.

Outra razão para estas diferenças de percepção e pouca preocupação com o tema, parece ser o fato de atuarem no interior do Estado, onde prevalece o pensamento de que “essas coisas não acontecem aqui”, o que pode denotar que as relações são mais próximas e mesmo atuando em ambientes competitivos, o ambiente organizacional das cooperativas isola ou diminui as situações de assédio ou, o que pode ser pior, as situações de assédio podem estar sendo naturalizadas em um ambiente caracterizado por ser mais rústico, com "pessoas duronas" ou que "todo mundo se conhece e se atura", minimizando as situações de assédio.

Também pode ser considerado o "discurso romântico" da área de Gestão de Pessoas em relação às discrepâncias das respostas dos entrevistados, ou seja, por se tratar da área responsável pela prevenção, esta busca passar a impressão ao entrevistador de que existem mecanismos de prevenção e que são usados corretamente dentro da organização, criando às vezes uma realidade imaginária para as cooperativas, que de fato pode não existir.

Uma melhoria que poderia ser feita diz respeito à comunicação, onde a área de Gestão de Pessoas das cooperativas deveria reavaliar todos os processos a fim de verificar se não há falhas de comunicação. Ter programas de prevenção ao assédio moral nas cooperativas não significa que todos dentro delas saibam a respeito dessas práticas. A comunicação deve ser benfeita a fim de evitar problemas, como foi observado nas diferentes respostas dos profissionais de Gestão de Pessoas e dos outros profissionais entrevistados e para evitar que situações de assédio possam ser naturalizadas ou minimizadas dada a falta de informação sobre o assunto.

Este trabalho aponta para a necessidade de novas pesquisas direcionadas para compreender melhor questões como: o posicionamento geográfico da organização (interior ou grande centro urbano) afeta a percepção e a discussão sobre assédio moral; de que forma a cultura de organizações cooperativistas influencia para minimizar ou maximizar a percepção 
do que vem a ser; e as diferentes abordagens de comunicação para trabalhar as ações de prevenção.

\section{REFERENCIAS}

Arendt, H. (1998). Sobre a violência. Rio de Janeiro: Relume Dumará.

Bardin, L. (2011). Análise de conteúdo. São Paulo: Edições 70.

Barreto, M. (2004). Assédio moral no trabalho: uma odisseia de sofrimento e incertezas. In Nunes Sobrinho, F. de P. \& Nassaralla, I. (Org.). Pedagogia institucional: fatores humanos nas organizações. Rio de Janeiro: Zit.

Bialoskorski Neto, S. (2002). Estratégias e cooperativas agropecuárias: um ensaio analítico. In Braga, M. J., \& Reis, B. S. dos (Org.). Agronegócio cooperativo - reestruturação e estratégias. Viçosa.

Bourdieu, P. (2010). A dominação masculina. Rio de Janeiro: Bertrand Brasil.

Brasil (2000). Ministério da Saúde. Secretaria de Políticas de Saúde. Política Nacional de Redução da Morbimortalidade por acidentes e violência. Revista de Saúde Pública, 34 (4), 427-430.

Campos, A. S. (2004). A violência como objeto para a saúde do trabalhador: agressões contra trabalhadores das unidades básicas de saúde do distrito sanitário norte de Belo Horizonte. 2004. Dissertação de mestrado, Faculdade de Medicina da Universidade Federal de Minas Gerais, Belo Horizonte.

Chaddad, F. R. (2007). Cooperativas no agronegócio do leite: mudanças organizacionais e estratégicas em resposta à globalização. Organizações Rurais \& Agroindustriais, 9 (1), 69-78. 
Dias Júnior, P. C. (2013, nov.). Cooperativismo agropecuário: câmara temática de insumos agropecuários. Sistema OCB: CNCOOP/OCB/SESCOOP, 1-22. Recuperado em 15 de abril, 2015 , de: $<$ http://www.agricultura.gov.br/arq_editor/file/camaras_tematicas/Insumos_agropecuarios/71RO/ app_ocb.pdf >.

Dellagnelo, E. H. L. \& Silva, R. C. (2005). Análise de conteúdo e sua aplicação em pesquisa na administração. In Vieira, M. M. F. \& Zovain, D. M. (Orgs.), Pesquisa qualitativa em administração: teoria e prática. São Paulo: FGV.

Farias, R. P. (2008, jan./abr.). Assédio moral e a empresa. Desafio: Revista de Economia e Administração de Campo Grande, 9, 104-110.

Ferreira, M. A. M. \& Braga, M. J. (2004, out). Diversificação e competitividade nas cooperativas agropecuárias. Revista de Administração Contemporânea, 8(4), 33-55.

Freitas, M. E. (2001, abr./jun.). Assédio moral e assédio sexual: faces do poder perverso nas organizações. Revista de Administração de Empresas, 41 (2), 8-19.

Freitas, M. E.; Heloani, J. R.; \& Barreto, M. (2008). Assédio moral no trabalho.

São Paulo: Cengage Learning, 2008.

Gosdal, T. C.; Soboll, L. A.; Schatzmam, M. \& Eberle, A D. (2009). Assédio moral organizacional: esclarecimentos conceituais e repercussões. In Gosdal, T. C.; Soboll, L. A. P. (Orgs.). Assédio moral interpessoal e organizacional: Um enfoque interdisciplinar. São Paulo: LTr.

Gonçalves, W. J. (2008, jan./abr.). Danos na relação de emprego e o reflexo no capital humano. Desafio: Revista de Economia e Administração de Campo Grande, 9 (17), 94-103. 
Heloani, R. (2004, jan./jun.). Assédio moral: um ensaio sobre a expropriação da dignidade no trabalho. Revista de Administração de Empresas, 3 (1), 1-18.

Hirigoyen, M. F. (2006). Mal-estar no trabalho: redefinindo o assédio moral (3a ed). Rio de Janeiro: Bertrand Brasil.

. (2008). El acoso moral en el trabajo: distinguir lo verdadero de lo falso (1a ed. $2^{\mathrm{a}}$ reimp). Buenos Aires: Paidós.

Lago, A. \& Silva, T. N. (2012). Condicionantes do desenvolvimento de relacionamentos intercooperativos no cooperativismo agropecuário. Organizações Rurais \& Agroindustriais, 14 (2), 212-226.

Nunes, T. S\& Tolfo, S. da R. (2012). Prevenção e desenvolvimento de uma política antiassédio moral no trabalho. In> EnANPAD, 35.,2012, Rio de Janeiro. Encontro Nacional da Anpad, Rio de Janeiro.

Oliveira, R. P. de; \& Nunes, M. de O. (2008, out.). Violência relacionada ao trabalho: uma proposta conceitual. Saúde e Sociedade, 17 (4), 22-34

Organização das Cooperativas Brasileiras (2014). Movimento livre da influência do Estado (2014). Recuperado em 19 de fevereiro, 2015, de: $<$ http://www.ocb.org.br/site/cooperativismo/evolucao_no_brasil.asp>.

Pinto, R. A. B.; \& Paula, A. P. P. (2013). Do assédio moral à violência interpessoal: relatos sobre uma empresa júnior. Cadernos Ebape.BR, 11(3), 340-355.

Rosa, A. R.; \& Brito, M. J. de. (2009). Ensaio sobre violência simbólica nas organizações. Organizações \& Sociedade, 16 (51), 629-646.

Santos, J. V. T. (2002, dez). Violências, América Latina: a disseminação de formas de violência e os estudos sobre conflitualidades. Sociologias, 8, 16-32. 
Gestão de Pessoas e Ações de Prevenção do Assédio Moral: Os Casos de Duas Cooperativas Agropecuárias do Paraná

Siqueira, M. V. S. (2009). Gestão de pessoas e discurso organizacional (2a ed.). Curitiba: Juruá.

Teixeira, R. F.; Munck, L.; \& Reis, M. C. D. (2011). Assédio moral nas organizações: percepção dos gestores de pessoas sobre danos e políticas de enfrentamento. Revista Gestão Organizacional, 4 (1) 30-48.

Teixeira, R. F., Reis, M. C. D., \& Santos, L. M. L. D. (2013). Assédio moral no trabalho: um estudo sobre as práticas de prevenção e combate ao fenômeno em empresas do norte do Paraná. Revista de Administração da UFSM, 6(4), 658-671. 